\title{
Perancangan Sistem Informasi Kunjungan Pasien Rawat Jalan di Rumah Sakit Muhammadiyah Bandung
}

\author{
Andika Dwi Prayoga*, Reza Adila Husaeni Tsabat, Yuda Syahidin, Leni Herfiyanti \\ Program Studi Informatika Rekam Medis \\ Politeknik Piksi Ganesha Bandung, \\ Jawa Barat, INDONESIA \\ adprayoga@piksi.ac.id*,rahtsabat@piksi.ac.id, yuad.syahidin@piksi.ac.id, leni.herfiyanti@piksi.ac.id
}

\begin{abstract}
The purpose of this study was to determine the patient visit information system at this hospital. By using qualitative research methods with a descriptive approach through observation, interviews, and literature studies, while for its development using the waterfall method through the stages of needs analysis, design, coding, implementation, and system testing which is carried out sequentially. This information system was created using Microsoft Visual Studio for databases using Microsoft Access. The problem that occurred in the previous system was that the data processing was still using Microsoft Excel so that the officer's data processing took a long time because it had to be done manually and had not been well integrated. With the information system designed, it is hoped that it can assist officers in processing patient visit data, and can also simplify and speed up officers in making outpatient visit reports because the information system designed is more effective and efficient. The conclusion of this outpatient visit information system design is that the information system is made more integrated and neatly organized.
\end{abstract}

Keywords: Patient Visits; Information Systems; Outpatients; Waterfall.

Abstrak - Tujuan dari penelitian ini yaitu untuk mnegetahui sistem informasi kunjungan pasien yang ada di rumah sakit ini. dengan menggunakan metode penelitian kualitatif dengan pendekatan deskriptif melalui observasi, wawancara dan studi pustaka, sedangkan untuk pengembangannya menggunakan metode Waterfall melalui tahapan-tahapan analisis kebutuhan, desain, pengkodingan, implementasi dan pengujian sistem tahapan tersebut dilakukan secara berurutan. Sistem informasi ini dibuat menggunakan Microsoft Visual Studio untuk database menggunakan Microsoft access Permasalahan yang terjadi pada sistem sebelumnya yaitu dalam pengolahan datanya masih menggunakan Microsoft excel sehingga dalam mengolah data petugas membutuhkan waktu yang lama, karena harus dkerjakan secara manual dan belum terintegrasi dengan baik. Dengan adanya sistem informasi yang dirancang ini diharapkan dapat membantu petugas dalam mengolah data kunjungan pasien, juga dapat mempermudah dan mempercepat petugas dalam pembuatan laporan kunjungan pasien rawat jalan, karena sistem informasi yang dirancang menjadi lebih efektif dan efisien. Kesimpulan dari perancangan sistem informasi kunjungan pasien rawat jalan ini sistem informasi yang dibuat menjadi lebih terintegrasi dan tertata dengan rapih.

Kata Kunci: Kunjungan Pasien; Sistem Informasi; Rawat Jalan; Waterfall.

1. Pendahuluan

Perubahan yang terjadi pada perkembangan teknologi sistem informasi saat ini menjadi salah satu faktor untuk dapat meningkatkan kualitas, sehingga dapat memberikan hasil yang lebih baik lagi untuk sistem yang akan digunakan [1]. Perkembangan teknologi yang sangat berpengaruh dalam kehidupan yaitu salah satunya pada bdang kesehatan [2]. Dalam bdang kesehatan tentunya banyak sekali teknologi yang digunakan baik untuk mengolah data, mengolah informasi dan juga digunakan untuk mengambil sebuah keputusan misalanya pada rumah sakit [3].

Rumah sakit merupakan sebuah organisasi yang menyelenggarakan beberapa layanan medik yang dari masa ke masa harus ditingkatkan kualitas pelayanannya dalam upaya meningkatkan mutu pelayanan kesehatan [4].

Khususnya pada pelayanan rumah sakit yaitu pada instalasi rawat jalan, dimana instansi rawat jalan ini imerupakan salah satu sumber pemasukan sistem pelayanan di rumah sakit [5]. Pelayanan rumah sakit akan berpengaruh terhadap minat kunjungan pasien. Petugas kesehatan, sarana juga prasarana di rumah sakit mempengaruhi kualitas rumah sakit itu sendiri. Petugas rumah sakit khususnya pada rawat jalan harus dapat mengolah laporan kunjungan pasien [6].

Rumah Sakit Muhammadiyah Bandung merupakan salah satu rumah sakit yang melayani pasien setiap harinya, tak terkecuali pada instalasi rawat jalan [7]. Data kunjungan pasien rawat jalani di rumah sakit ini masih dkelola menggunakan Microsoft Excel dari hasil rekapan rekam medis pasien rawat jalan. Seiring bertambahnya 
jumlah kunjungan pasien rawat jalan setiap harinya di Rumah Sakit Muhammadiyah Bandung ini memberikan dampak pada pengolahan data pasien rawat jalan yang semakin meningkat, sehingga perlu adanya sistem yang dapat menunjang kegiatan tersebut. Rumah Sakit Muhammadiyah Bandung ini untuk sistem yang digunakan sudah terkomputerisasi tetapi untuk meningkatkan kualitas sistem informasi dibutuhkan perancangan sistem baru yang lebih efisien dan efektif terutama dalam pembuatan laporan dan juga penyimpanan data-data [8].

Sistem informasi yang dibuat ini bertujuan untuk meningkatkan kualitas Sistem yang ada di Rumah Sakit Muhammadiyah Bandung agar lebih terintegrasi dengan baik juga dalam mengolah data menjadi lebih efisisen dan efektif [9]. Petugas rumah sakit juga akan merasa terbantu dengan adanya sistem yang dirancang ini karena dapat memudahkan dan mempercepat pekerjaan [10].

\section{Metodologi}

Metode penelitian yang digunakan yaitu metode kualitatif dengan pendekatan secara deskriptif dengan melakukan teknik pengumpulan Data melalui observasi, wawancara dan studi pustaka, sedangkan metode yang digunakan untuk pengembangan pada perangkat yaitu metode Waterfall (air terjun). Berikut ini teknik pengumpulan data yang dilakukan:

\section{A. Teknik Pengumpulan Data}

Pengumpulan data pada penelitian ini menggunakan observasi, wawancara, dan studi pustaka. Observasi dilakukan dengan icara pengamatan secara langsung terhadap kunjungan pasien rawat jalan di rumah sakit. Data hasil observasi ini menjadi bahan penelitian untuk merancang Sistem perangkat lunak. Sementara wawancara dilakukan langsung mewawancarai petugas yang terkait untuk dimintai penjelasan mengenai sistem kunjungani pasieni di rumah sakit. Dan pada studi pustaka dilakukan melalui penelitian yang sudah pernah dilakukan serta pada referensi artikel pada website yang berhubungan langsung dengan penelitian ini untuk dijadikan bahan pengembangan penelitian.

\section{B. Metode Pengembangan}

Metode pengembangan perangkat lunak ini menggunakan metode $W$ aterfall (air terjun). Metode ini dilakukan secara berurutan sesuai tahapan-tahapan yang akan dilakukan. Berikut ini merupakan Gambar dan tahapan-tahaan yang dilakukan dalam pengembangan sistem perangkat lunak, Gambar 1.

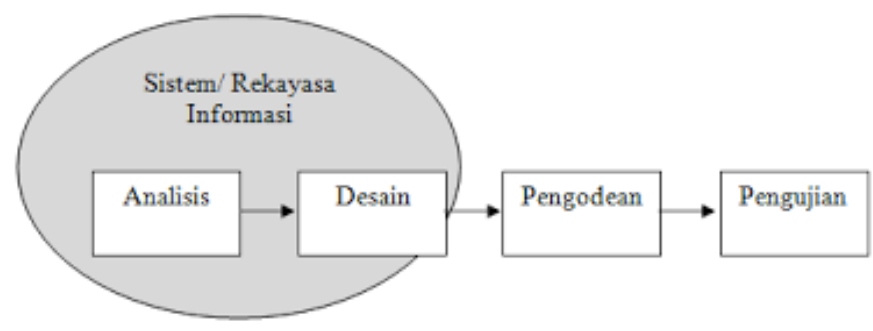

Gambar 1. Metode $W$ aterfall

Berikut ini merupakan tahapan-tahapan yang digunakan:

1) Analisis

Pada tahap analisis ini merupakan tahapan yang digunakan untuk mengidentifikasikan terlebih dahulu Sistem yang akan dirancang. Menganalisisi terlebih dahulu permasalahan yang terjadi pada sistem perangkat lunak sebelumnya agar menjadi acuan untuk memperbaiki dan mengembangkan perangkat lunak ini, juga menganalisis kebutuhan untuk perangkat lunak yang akan dirancang.

\section{2) Desain}

Desain ialah tahapan dimana menerjemahkan dari hasil analisis kebutuhan menjadi sebuah rancangan sebelum ke tahapan pengkodingan, rancangan yang dilakukan meliputi perancangan pada basis data dan desain tampilan pada interface sistem.

3) Pengkodingan

Tahapan pengkodingan dilakukan menggunakan Microsoft Visual Studio 2012 dengan menggunakan Bahasa pemograman Visual Basic dan menggunakan Microsoft Access untuk database. Pengkodingan ini bertujuan agar Sistem yang dirancang ini dapat berjalan sesuai perintah yang ditentukan.

\section{4) Implementasi}

Merupakan tahapan merealisasikan aplikasi yang dibentuk menggunakan Microsoft Visual Studio 2012 dengan database yang digunakan yaitu Microsoft Access. Tahapan ini untuk menunjukkan tampilan yang sudah dibuat dalam aplikasi ini.

\section{5) Pengujian}

Tahapan pengujian ini dilakukan untuk mengetahui apakah sistem perangkat lunak sudah berfungsi dengan benar atau belum. Apabila terdapat error pada tahapan pengujian ini akan langsung dilakukan pengecekan kembali terhadap problem solving yang terjadi. Sehingga pada saat petugas menggunakan sistem ini akan berjalan dengan lancar. 


\section{Hasil dan Pembahasan}

\section{A. Hasil Analisis Sistem}

Analisis permasalahan pada sistem: kendala yang dihadapi yaitu dalam pembuatan laporan yang dilakukan untuk menghasilkan sebuah informasi masih dilakukan secara manual dengan menggunakan Microsoft Excel sehingga pada pembuatan laporan petugas membutuhkan waktu lama dikarenakan petugas harus merekap data terlebih dahulu. Permasalahan lain yang dihadapi yaitu perangkat satu dengan perangkat lainnya belum terhubungi sehingga menyulitkan penyimpanan data yang cepat dan tepat karena data yang sudah dkerjakan harus dilakukan penyimpanan secara manual pada perangkat lainnya. Hal ini bisa imenyebabkan adanya perubahan data yang tersimpan.

Analisis kebutuhan pada sistem: kebutuhan yang diharapkan pada perancangan sistem ini yaitu sebuah sistem yang mampu membantu mempermudah petugas dalam mengolah data-data pasien dan juga dalam pembuatan laporan dengan waktu yang cepat dan menyimpan data secara otomatis. Sistem informasi yang dirancang ini dilengkapi dengan form login sehinggai hak akses menjadi terbatas hanya petugas yang dapat mengakses sistem ini. Sistem ini dapat melakukan penginputan data pasien yang berkunjung maupun yang melakukan pendaftaran pasien baru. Dengan adanya sistem ini petugas dapat melihat data laporan jumlah kunjungan pasien rawat jalan.

\section{B. Perancangan Sistem}

\section{1) Use Case Diagram}

Use case diagram merupakan sebuah interaksi antara satu aktor atau lebih dengan sistem informasi yang akan dirancang. Aktor ini memiliki hak akses dalam penggunaan sistem informasi. Pada Gambar 2 perancangan sistem ini terdapat dua aktor yaitu admin Petugas pendaftaran dan kepala rumah sakit, dimana admin pendaftaran dapat mengakses mulai dari login, input pendaftaran pasien, mengolah data kunjungan poliklinik, mengolah data dokter dan mengolah laporan, sedangkan kepala rumah sakit dapat mengakses dan melihat laporan yang sudah dibuat oleh admin.

\section{2) Activity Diagram}

Activity diagram pada Gambar 3 ialah suatu aliran atau aktivitas kerja dari sebuah sistem yang dirancang. Aktivitas sistem yang dirancang ini yaitu dimulai dengan admin harus melakukan login terlebih dahulu dengan memasukkan username dan password kemudian sistem akan menampilkan halaman utama atau menu utama, admin akan memilih menu apakah mengolah pendaftaran pasien, mengolah kunjungan poliklinik, mengolah data dokter atau mengolah laporan. Sistem ini akan menyimpan data yang telah diolah oleh admin. Apabila kepala rumah sakit akan mengecek laporan maka sistem ini akan menampilkan data laporan.

\section{3) Class Diagram}

Pada Gambar 4 dibawah ini menggambarkan dari kelas-kelas yang akan dibuat untuk merancang sistem, kelas-kelas ini disebut juga class diagram atau atribut.

\section{Implementasi}

Implementasi ini merupakan gambaran interface dari sistem yang sudah dibuat dimana terdiri dari form login, form pasien, poliklinik, form dokter, laporan kunjungan pasien, kunjungan poliklinik dan laporan dokter. Berikut ini tampilan-tampilan pada rancangan sistem yang sudah dibuat.

Pertama kali sebelum dapat mengakses sistemnya yang harus dilakukan yaitu login terlebih dahulu dengan memasukkan username dan password pada Gambar 5 dibawah ini. Apabila login berhasil akan muncul menu utama atau halaman utama seperti pada Gambar 6.

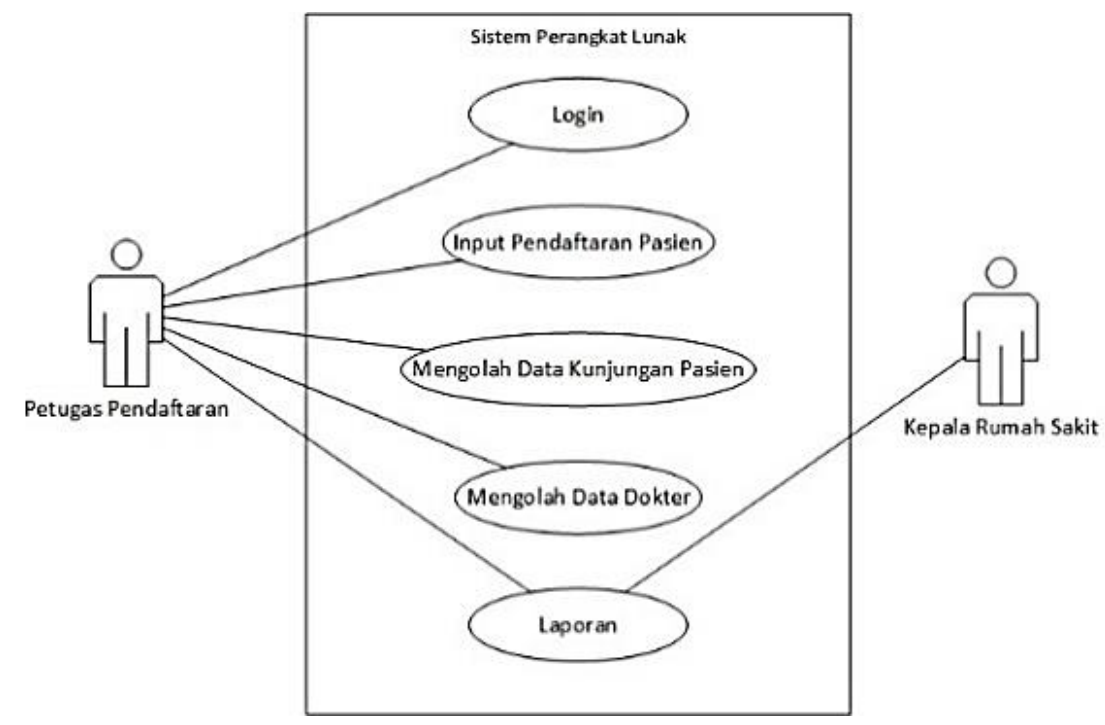

Gambar 2. Use Case Diagram 


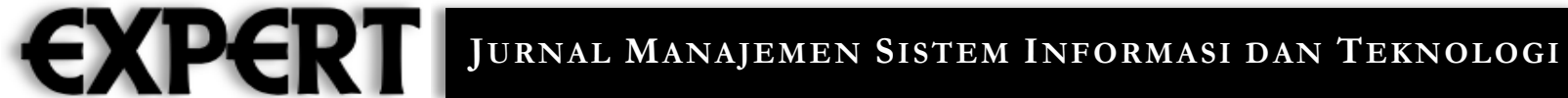

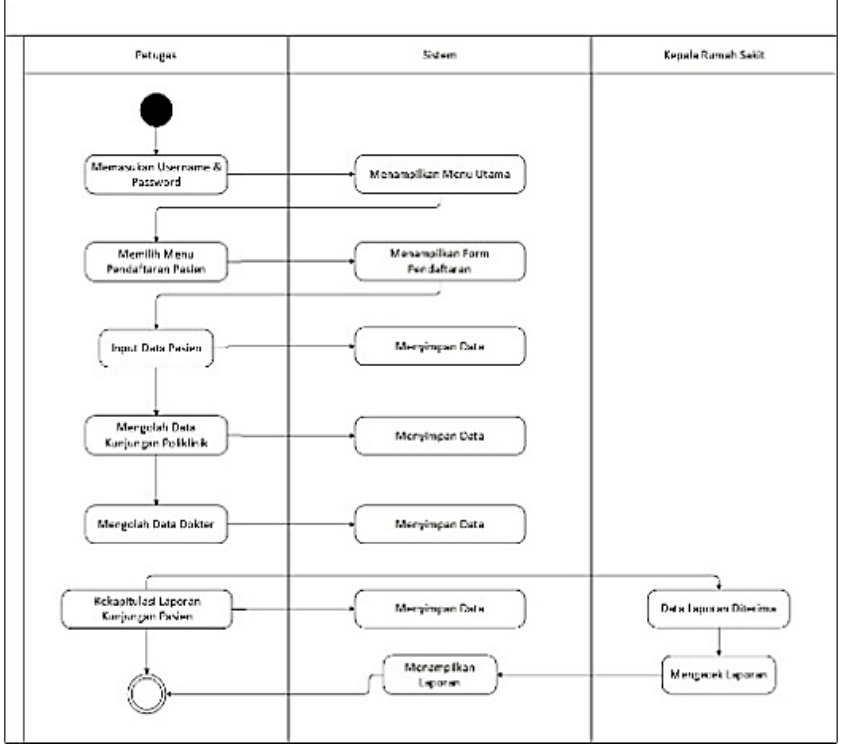

Gambar 3. Activity Diagram

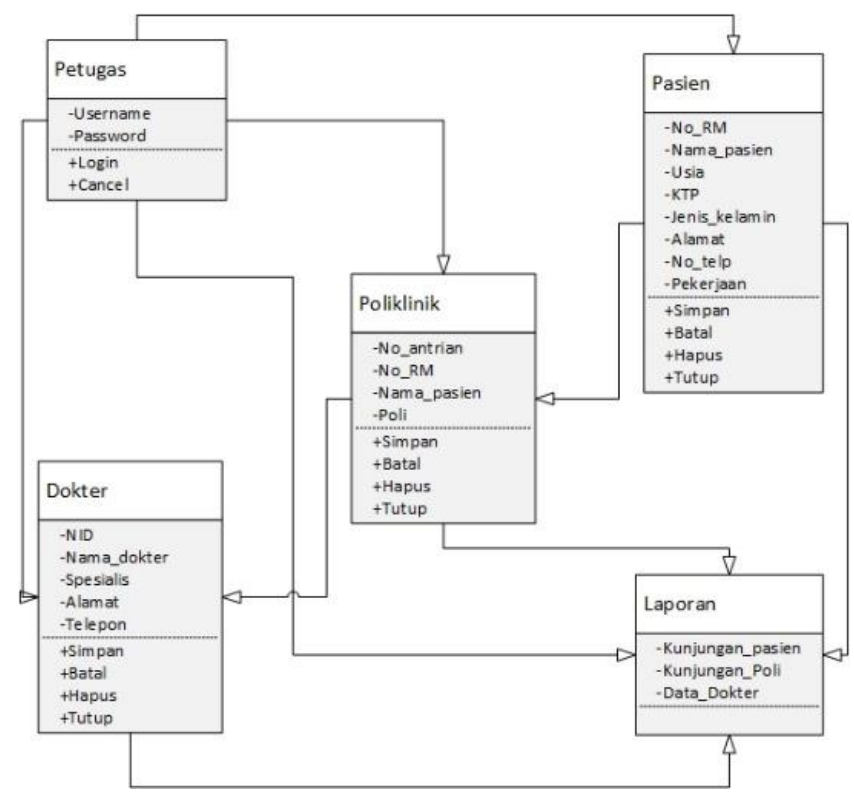

Gambar 4. Class Diagram

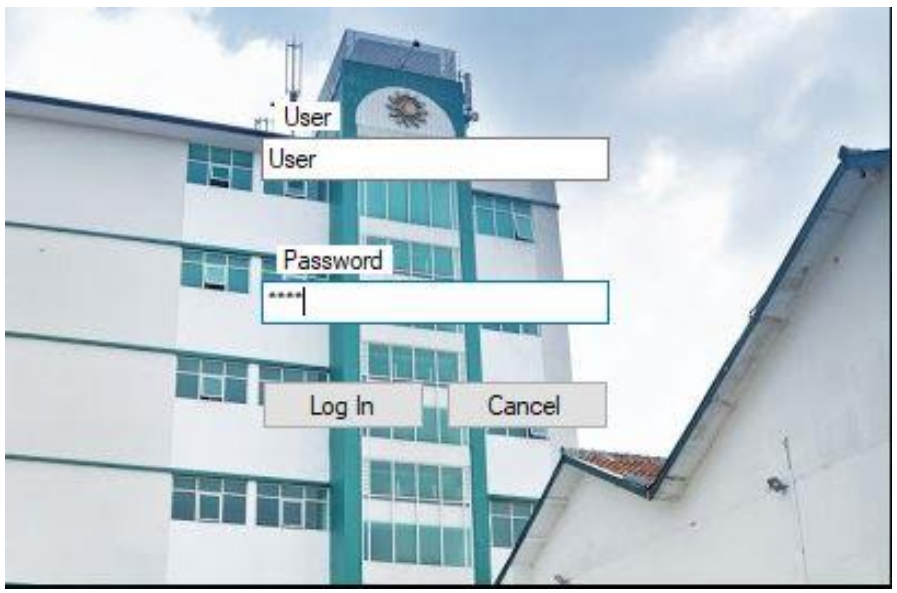

Gambar 5. Login 


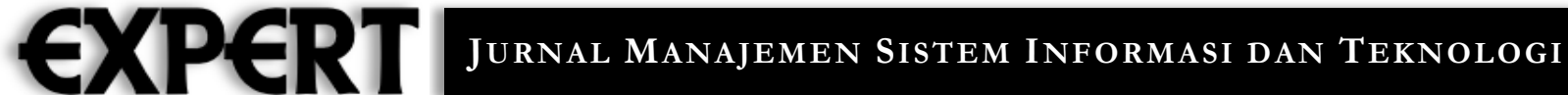

Pada menu utama terdapat beberapa item menu diantaranya form pasien, form pasien ini diisi oleh petugas pendaftaran, sebelum pasien menuju poliklinik yang dituju, kemudian petugas bisa menyiman data pasien ini secara otomatis seperti pada tampilan Gambar 7 ini.

Setelah mengisi data pasien petugas pendaftaran menanyakan pasien akan ke poli mana, lalu mengisi data pada form poli pada Gambar 8 ini. Pada Gambar 9 sistem ini juga terdapat form dokter dimana form ini berisi datadata dokter. Sedangkan Gambar 10 menunjukkan laporan kunjungan pasien, Gambar 11 menunjukkan laporan kunjungan pada poliklinik dan pada Gambar 12 menunjukkan laporan data dokter.

\section{Pengujian Sistem}

Pengujian sistem merupakan tahapan dimana menguji Sistem yang sudah dibuat apakah sudah berfungsi dengan benari, Pengujian sistem ini juga dapat melihat jika ada salah satu error yang terdapat pada saat merancang sistem ini. Pada tahap pengujian sistem ini menggunakan metode Black Box Testing.

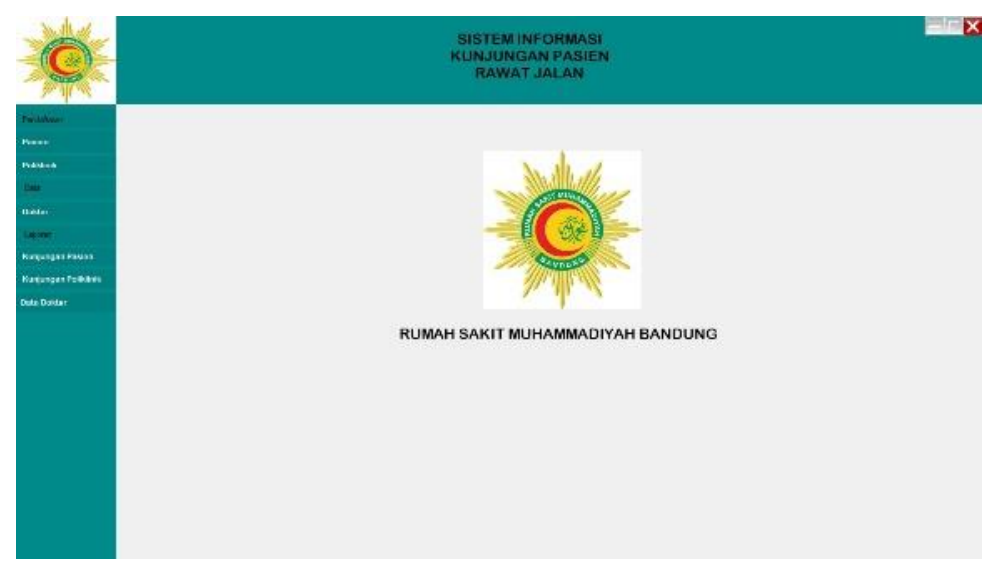

Gambar 6. Menu Utama

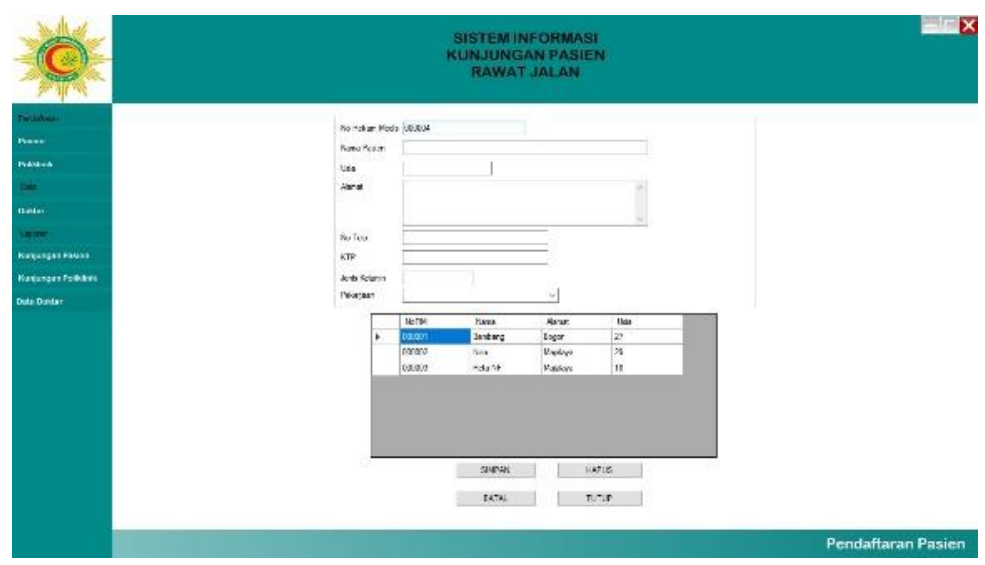

Gambar 7. Form Pasien

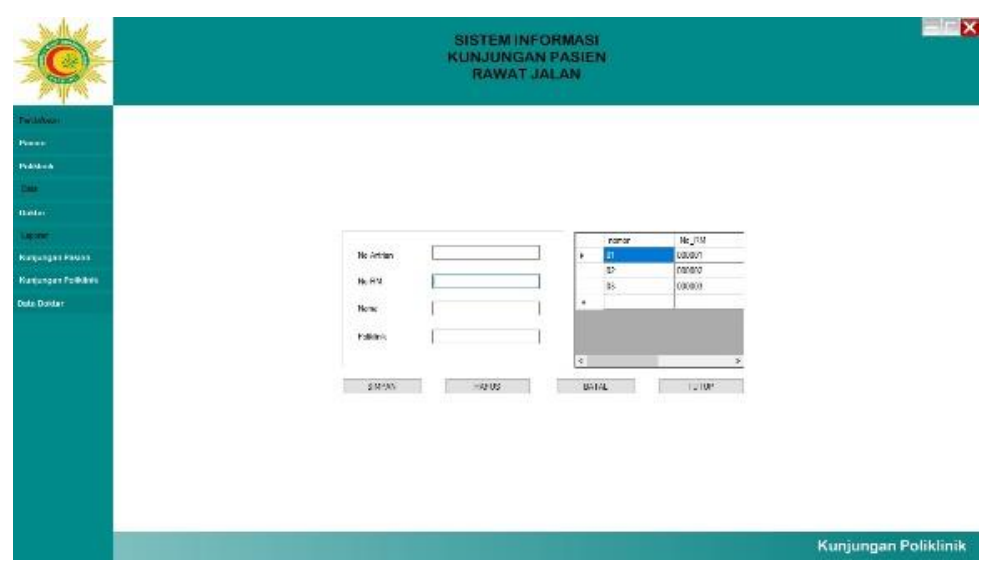

Gambar 8. Form Poliklinik 


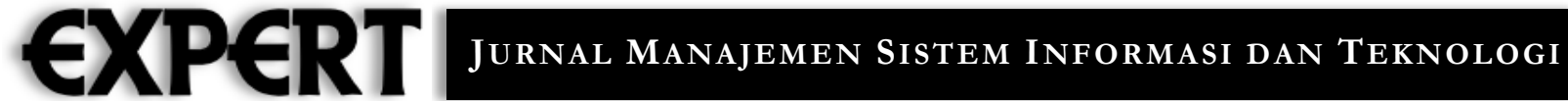

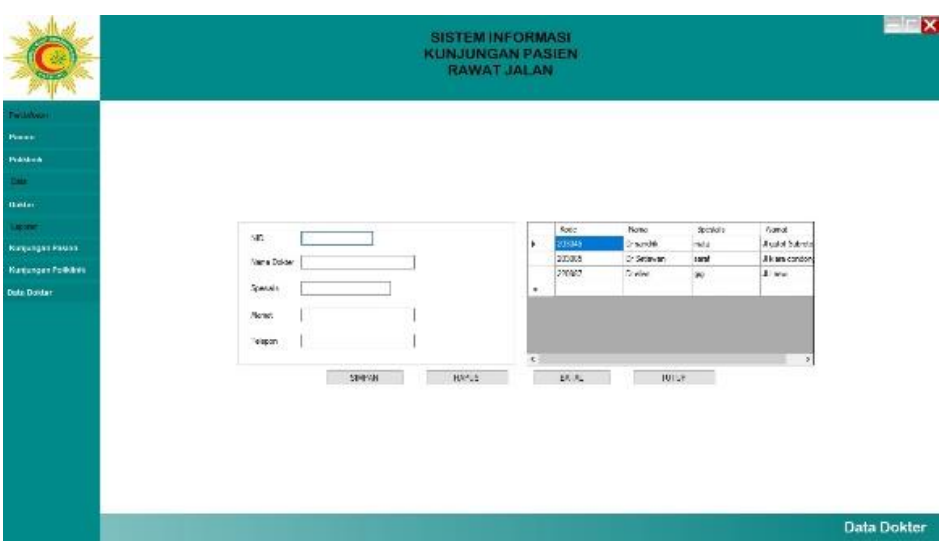

Gambar 9. Form Dokter

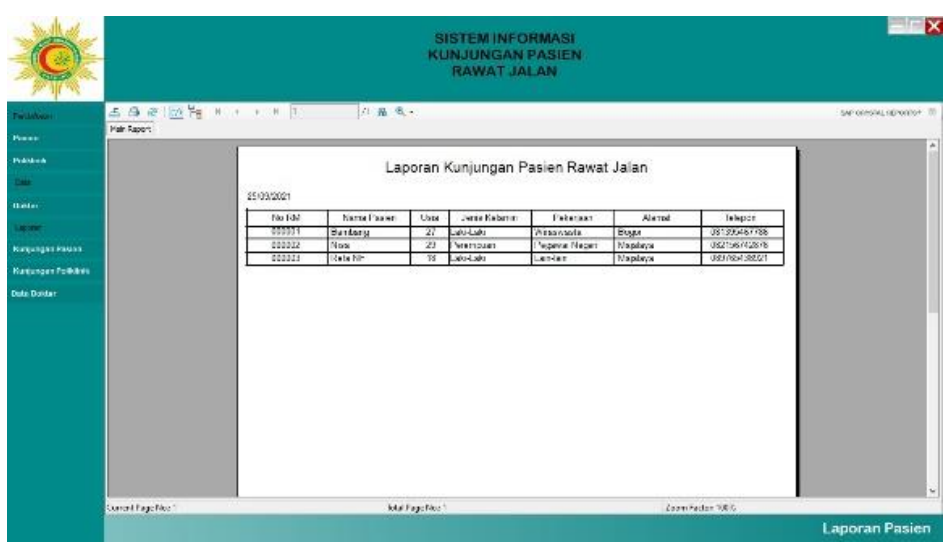

Gambar 10. Laporan Kunjungan Pasien

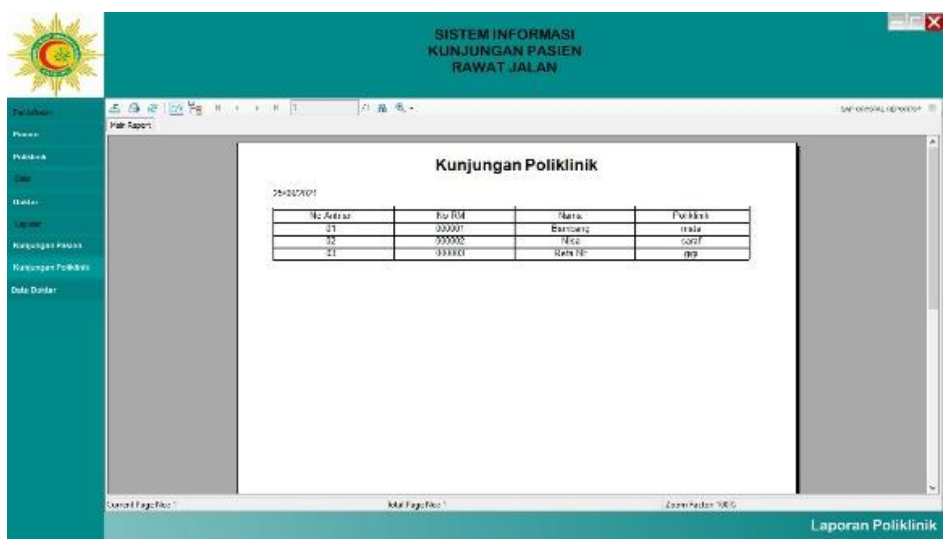

Gambar 11. Laporan Kunjungan Poliklinik

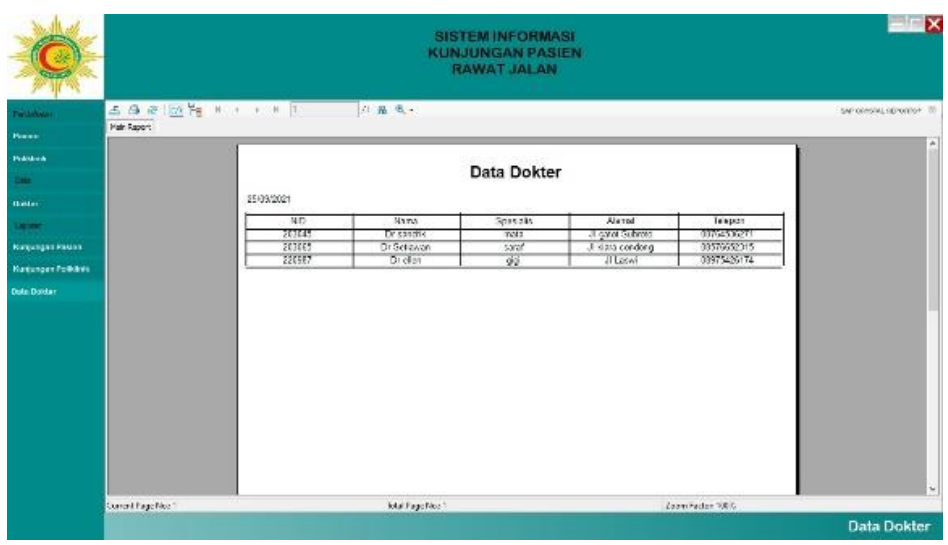

Gambar 12. Laporan Data Dokter 


\section{Kesimpulan}

Dengan adanya sistem informasi kunjungan pasien rawat jalan ini dalam proses kegiatan pelayanan pada rumah sakit ini diharapkan dapat memberikan perubahan, serta dapat dijadikan sebagai salah satu solusi dan upaya untuk memecahkan permasalahan yang terjadi, sehingga proses pengolahan kunjungan rawat jalan bisa dilakukan secara komputerisasigan dasar keamanan web mulai dari SQL Injection, CSRF, dan XSS tanpa perlu dibuat dari awal seperti pada PHP Native.

\section{Daftar Pustaka}

[1] R. Melyanti, D. Irfan, A. Febriani, R. Khairana, and S. Hang Tuah Pekanbaru, "Rancang Bangun Sistem Antrian Online Kunjungan Pasien Rawat Jalan pada Rumah Sakit Syafira Berbasis Web," J. Inf. Technol. Comput. Sci., vol. 3, no. 2, pp. 192-198, 2020, doi:

https://doi.org/10.31539/intecoms.v3i2.1676.

[2] I. Tanjung, "Perancangan Sistem Informasi Rekam Medis Terpadu dalam Upaya," J. Intra-Tech, vol. 1, no. 1, pp. 43-54, 2017, [Online]. Available: https://www.journal.amikmahaputra.ac.id/index.p $\mathrm{hp} / \mathrm{JIT} /$ article/view/3.

[3] A. Prasetyo and M. S. Azis, "Perancangan Sistem Informasi Rekam Medis pada Puskesmas Jomin Berbasis Web," J. Interkom J. Publ. Ilm. Bid. Teknol. Inf. dan Komun., vol. 13, no. 2, pp. 31-38, 2021, doi: 10.35969/interkom.v13i2.47.

[4] M. Apri, D. Aldo, and Hariselmi, "Simulasi Monte Carlo untuk Memprediksi Jumlah Kunjungan Pasien," vol. 7, no. 2, 2019, doi: https://doi.org/10.47024/js.v7i2.176.
[5] A. N. Renny and P. Beni, "Analisis dan Perancangan Sistem Informasi Rekam Medis di Rumah Sakit Tk. IV dr. Bratanata Jambi," J. Manaj. Sist. Inform., vol. 1, no. 2, pp. 147-158, 2016, [Online]. Available: http://ejournal.stikomdb.ac.id.

[6] Y. S. Waluyo, R. Sari, and E. Oktavianti, "Perancangan Sistem Informasi Pembelajaran Berbasis Web," Multinetics, vol. 3, no. 2, p. 45, 2017, doi: 10.32722/vol3.no2.2017.pp45-48.

[7] H. Rohman and M. Wulandari, "Sistem Informasi Manajemen Rawat Jalan di Klinik Pratama: Surat Keterangan Medis, Laporan Kunjungan Pasien, Obat, Pembayaran," J. Inform. dan Rekayasa Perangkat Lunak, vol. 1, no. 2, pp. 115-123, 2019, doi: 10.36499/jinrpl.v1i2.2956.

[8] N. Ardista, P. Purbandini, and T. Taufik, "Rancang Bangun Data Warehouse untuk Pembuatan Laporan dan Analisis pada Data kunjungan Pasien Rawat Jalan Rumah Sakit Universitas Airlangga Berbasis Online Analytical Processing (OLAP),"J. Inf. Syst. Eng. Bus. Intell., vol. 3, no. 1, p. 40, 2017, doi: 10.20473/jisebi.3.1.40-51.

[9] L. W. Utami, P. Purwaningsih, and L. Ni'mah, "Fundamental and Management Faktor yang Mempengaruhi Penilaian Terhadap Penurunan Tingkat," Fmnj, vol. 2, no. 2, pp. 69-74, 2020, doi: http://dx.doi.org/10.20473/fmnj.v2i2.15737.

[10] M. Tabrani, "Implementasi Metode Waterfall pada Perancangan Sistem Informasi Pelayanan Rawat Jalan Puskesmas Telagasari Karawang," Indones. J. Bus. Intell., vol. 2, no. 2, p. 79, 2019, doi: 10.21927/ijubi.v2i2.1125. 